\title{
Highlights from latest sea-operations in the Macaronesian region with unmanned autonomous marine gliding vehicles
}

\author{
Carlos Barrera, Tania Morales, Josué Viera, Álvaro \\ Lorenzo, Daura Vega, Octavio Llinás \\ Oceanic Platform of the Canary Islands - \\ Carretera de Taliarte s/n, 35200 Telde, Spain \\ e-mail: carlos.barrera@plocan.eu
}

\begin{abstract}
Current advances on key marine technology fields provide nowadays a broad range of autonomous unmanned platforms addressed for an efficient and cost-effective ocean observation, with a suitable level of success in terms of endurance, reliability and useful gathered information. In this context, a multidisciplinary family of unmanned autonomous vehicles addressed to monitor both coastal and open-ocean areas plays a relevant role. Over the last months, some of the newest unmanned gliding-vehicle technologies have been tested within the context of the Oceanic Platform of the Canary Islands (PLOCAN) in varied operational scenarios aiming different technical and scientific purposes, all of them joined in direct partnership with the company provider and other $R \& D$ institutions in some cases. Among others, representative examples in this way are the missions under the name Challenger One, Volcano and SB02 through surface and underwater gliding vehicles, performed mostly in the surrounding subtropical waters of the ESTOC ocean observatory in the Canary Islands archipelago. The main gathered operational and scientific results from these missions are presented in this work as a sign of new ocean observing technologies within the framework of the Macaronesian Marine and Maritime Observation Strategy (R3M) and linked with the current European rules, programs and projects in this field.
\end{abstract}

Keywords - autonomous vehicle, gliders, R3M, ocean observatory, monitoring, marine robotics, ESTOC

\section{INTRODUCTION}

The marine environment is a complex and turbulent system where strong interactions between physical, chemical, and biological processes take place. The interaction of these processes occur on scales from a few meters to thousands of kilometers in space and from hours to more than decades in time, which makes it particular challenging to investigate. One basic requirement for a comprehensive analysis of the marine environment is the simultaneous acquisition of the various physical, chemical, and biological parameters. Another requirement is to observe the wide range of spatial and temporal scales. It is clear that only the structured interplay of a variety of observing system components can keep with this challenge.

\author{
María José Rueda \\ Instituto Canario de Ciencias Marinas \\ ICCM \\ Telde, Spain \\ mjrueda@iccm.rcanaria.es
}

The international Global Ocean Observing System (GOOS) has been set up to value and organize the different marine observing components into one coherent system. GOOS is a contributor to the Global Earth Observation System of Systems (GEOSS), which exists to monitor the environment and assist stakeholders in taking decisions [1]. The current design of GOOS is not optimized in sampling capabilities (e.g. eastern and western boundary currents are not well sampled) as well as parameter space (e.g. marine ecosystem state variables are only very poorly resolved). It will be shown in this work how gliders can help to further optimize GOOS in a regional context as is the Macaronesian region. Nowadays there is a new research strategy concept in the area supported meanly by Azores, Madeira and Canaries through the named R3M (Macaronesian Marine and Maritime Network).

\section{IN-SITU OCEAN OBSERVATIONS IN THE MACARONESIAN REGION}

In-situ observations of the marine environment of the Macaronesian region have been traditionally carried out by oceanographic ships, moorings, and floats, through several research programs and projects like MACSIMAR, Red ACOMAR, ALERMAC, CLIMARCOST, CLIMAAT, ESTOC, R3M, MaReS, among others. Used observing platforms in these projects can carry out multidisciplinary measurements of the ocean, but not always with the spatiotemporal resolution required. The key point here is to avoid any aliasing effect leading to erroneous conclusions. During the last 30 years, an increasing number of actions designed to estimate the ocean state or observe how climate change has unfolded in the ocean. Among those one can distinguish four in-situ observing strategies:

- $\quad$ Process studies: many oceanic processes require further investigation and require in-situ observations that are able to resolve small and (sub)meso scale (1$100 \mathrm{~km}$, days/weeks), in relatively large areas (regions/basin) to be carried out.

- Observatories: often with a multidisciplinary approach, observatories are set for decades in 
particular areas (defined by a global vision as much as possible) to focus on particular processes defined by provinces that are characterized by a strong interannual variability.

- Observing systems for scientific projects: many scientific projects aim to address the oceanic variability at low frequency and have set up observing systems to allow relatively long term observations (years) like repeated transoceanic sections and water samples collection in particular areas (on a week/month to multi-year basis) or mooring arrays (periods of years at a resolution of a few minutes).

- Operational oceanography: the main focus is the real time data coverage and flow of information, as well as archiving, with the major constraint of real time and delayed-mode quality controls.

The widest variety of multidisciplinary measurements at high spatial resolution can be obtained from oceanographic research vessels. Unfortunately, logistic and economic aspects often invalidate them as platforms able to carry out continuous and sustained ocean observations. While analyses of hydrographic sections have shown changes between surveys it is often not clear what they mean. With less capacity for the measured parameters, ships of opportunity can be used for ocean monitoring but they are constrained to (commercial) timetables and maritime routes.

Moorings provide multidisciplinary data with very high temporal resolution over long periods. Nowadays, moorings can operate for more than five years. Satellites and surface buoys and/or submarine cables for data transmission can convert them into sustained ocean observing platforms, allowing near real time data transfer to land bases. Results from moored systems at key locations have documented large variability but it is difficult to extract trends. The spatial resolution is very poor.

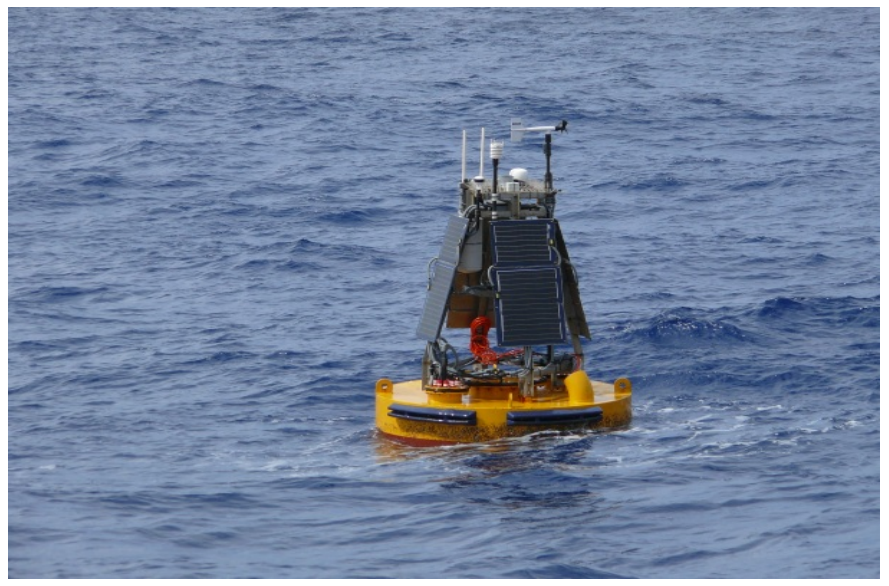

Fig. 1. Surface buoy at ESTOC site supporting a deep-ocean multidisciplinary mooring over 3618 meters depth and 60 nautical miles off Gran Canaria. ARGOS satellite link for real-time telemetry.

The international Argo program has been very successful in providing the first intensive data coverage of temperature and salinity in the upper 1000 to $2000 \mathrm{~m}$ of the world ocean. This global array of profiling floats has been recently implemented and is a network capable of monitoring the global ocean in a full operational sense.

A large number of floats makes it possible to monitor the ocean "randomly" and "on average" in a global manner, each float providing data every 10 days or so. The present array configuration of $\sim 3000$ floats gives a horizontal resolution (average distance between floats) of around $300 \mathrm{~km}$, in case the floats would be distributed evenly, and which is adequate to derive mean quantities as the average heat content or temperature on time scales of month. This is a rather coarse spatial and temporal resolution, which is difficult to increase.

The number of floats required varies roughly quadratically with the average horizontal resolution of the system and in addition, floats drift out of divergent regions and into convergence regions according to the currents, which leads to uncontrolled gaps in the data coverage. Currently, the Argo program concentrates on physical measurements only but advances in biogeochemical sensors may soon open the array for multidisciplinary research.

The Oceanic Platform of the Canary Islands -PLOCAN- is a public consortium facility engaged to promote science and technology developments in the marine and maritime sectors through a cost-effective and sustainable multipurpose services combination as observatory, test site, underwater vehicles base -VIMAS-, highly specialized training and innovation hub. PLOCAN staff operates a wide range of glider technologies since 2007 both by its own as well as in-partnership with national and international technological base institutions and companies at regional -Macaronesia- and basin -Atlanticscales into the framework of national and EU projects, technological development cooperation and specific "ondemand" services.

ESTOC site is the European Station for Time- Series in the Ocean [2] [3], located 60 nautical miles northwards the Canarian Archipelago over $3670 \mathrm{~m}$ depth, and addressed for long-term studies in the Eastern North Atlantic. Operational since 1992, nowadays is supported by PLOCAN by a multidisciplinary set of autonomous observing platforms, where gliders play a key role. ESTOC represents a reference site for the R3M observations strategy program.

\section{GLIDER TECHNOLOGY}

Gliders have enhanced capabilities, when compared with profiling floats, by providing some level of maneuverability and hence position control. Gliders are buoyancy driven autonomous underwater vehicles able to perform saw-tooth trajectories from the surface to depths of $1000 \mathrm{~m}$. (for now), along reprogrammable routes using two-way communication via satellite [4] [5]. 


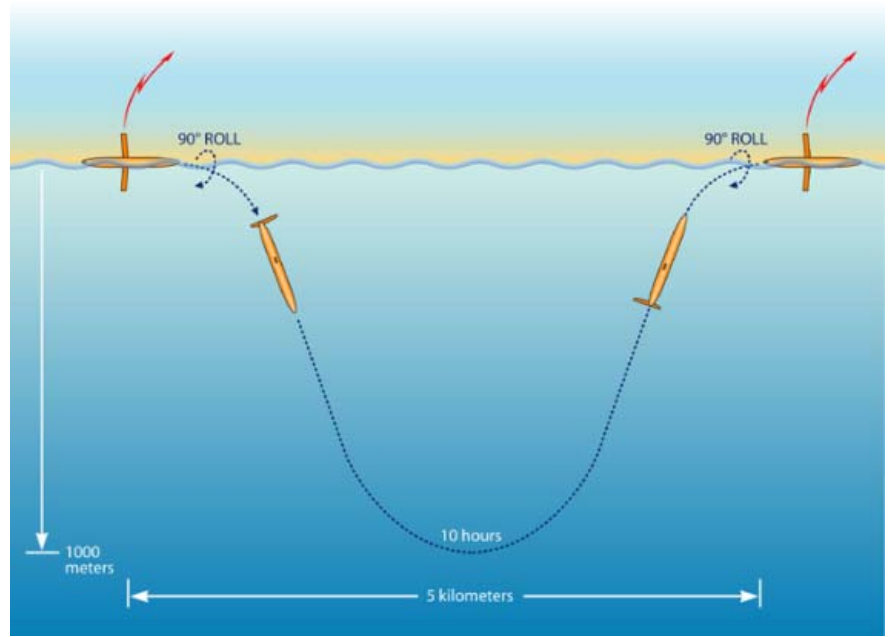

Fig. 2. The glider technology operational concept

They achieve forward speeds of up to $40 \mathrm{~km} /$ day thanks to wings and rudders, and can be operated for a few months before they have to be recovered [6] [7] [8]. Gliders can record physical and biogeochemical parameters during the dives. Even passive and active acoustic instruments have successfully been used. At each surfacing, they connect to a computer on land via the bidirectional Iridium satellite phone system in order to send the data they collected and receive new commands from the operator in land, if necessary (at a rate of about $30-60 \mathrm{Kbytes}$ in 5 minutes every $\sim 4-5$ hours). Gliders are considered to be less susceptible to damage from fish trawling than moorings and hourly/daily communication by satellite means that if a vehicle is lost or damaged the loss of data can be minimized. Replacing a glider is relatively easy and cheap compared to other operations at sea.

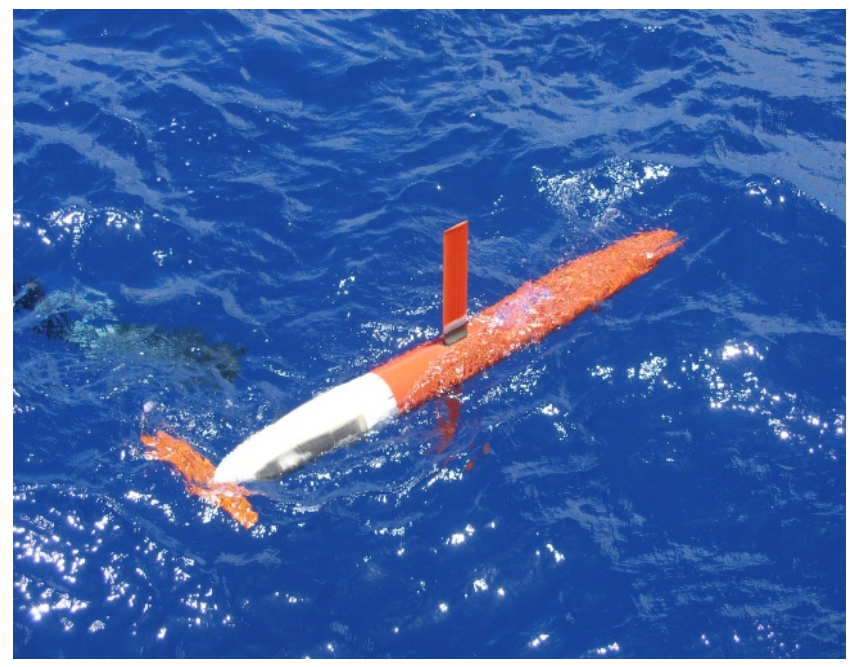

Fig. 3. The underwater glider concept.

First conceived in 1986, the concept of use was developed in 1989 with the first prototype flight tests carried out in 1991 [9] and after a 'teenager' period starting around 2002, gliders are now being incorporated into the operational technology portfolios of many research institutions and agencies. It has been demonstrated that gliders are able to carry out high resolution measurements of not only physical (temperature and salinity as well as average velocities over a dive) but also biogeochemical parameters such as dissolved oxygen and fluorescence/optical backscattering at various angles and wavelengths (giving estimates of the Chla, Colored Dissolved Organic Matter CDOM, and Phycoerythrin concentrations, as well as the water turbidity and particle sizes). An example of data collected by a glider is shown in Figure 6, but there are many other experiments reported in the literature [10] [11], demonstrating that gliders can cover transects of hundreds of $\mathrm{km}$, gathering physical and a biogeochemical data, on a long term basis (several months per deployment). Gliders can even contribute to studies on the behavior of whales through acoustic sensors.

\section{A. Slocum $G 2$}

The G2 Slocum glider is a versatile remote sensing AUV for ocean research and monitoring. Buoyancy driven, the long range and duration capabilities of this unmanned underwater vehicle technology make them ideally suited for water column observations. The interchangeable nose pump sections and science bay sensor suites give users the flexibility to optimize their glider fleet as mission requirements change [12] [13].

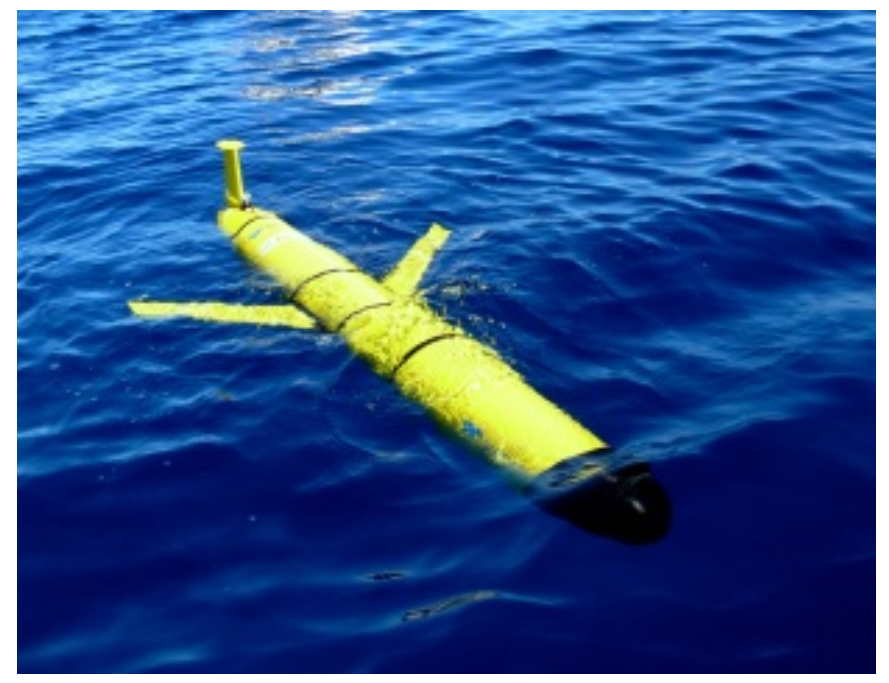

Fig. 4. Slocum G2 glider.

\section{B. Seaglider $1 K$}

The autonomous underwater vehicle (AUV) Seaglider $1 K A$ is a deep-diving AUV designed for missions lasting many months and covering thousands of miles, able to monitor several physical and biogeochemical water-column parameters, sending back data in near-real-time using global satellite telemetry [15]. 


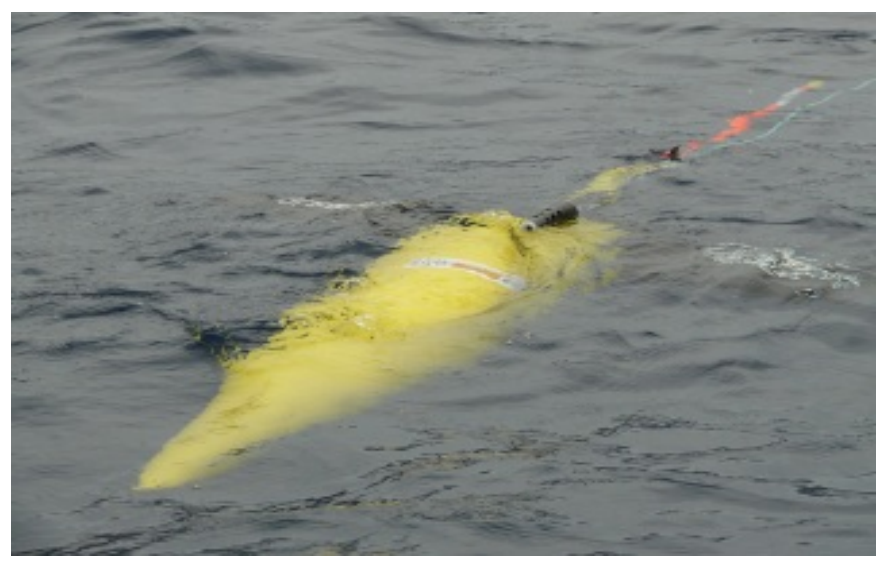

Fig. 5. Seaglider $1 \mathrm{~K}$ glider technology concept.

\section{Waveglider}

The Wave Glide, a surface unmanned autonomous marine robot [14] that represents an innovative approach to ocean persistent presence. It harnesses ocean wave energy to provide essentially limitless propulsion while solar panels continually replenish the batteries used to power the Wave Glider's control electronics and payload systems. The vehicle is propelled by the purely mechanical conversion of ocean wave energy into forward thrust, independent of wave direction.

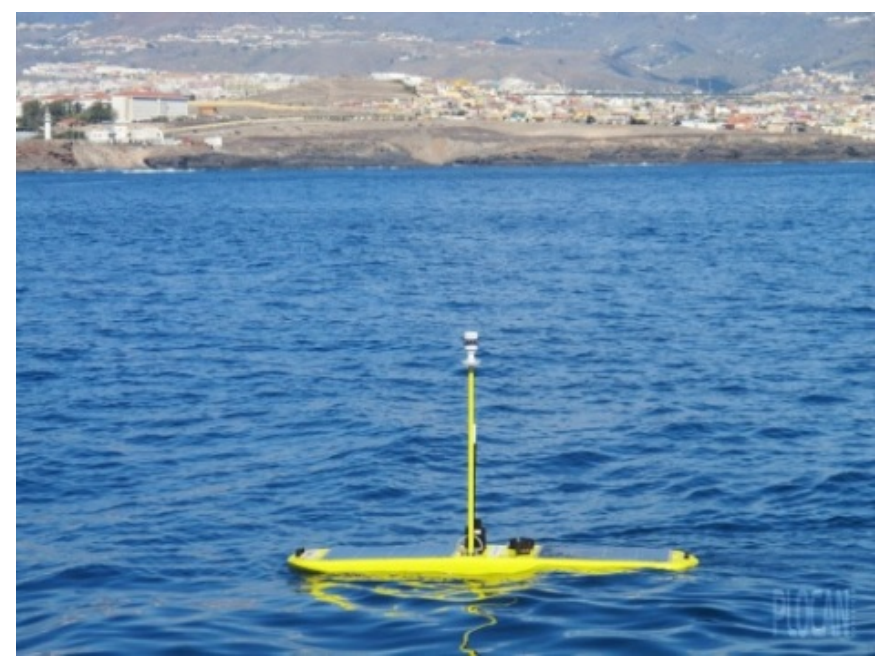

Fig. 6. The Waveglider technology.

\section{Sailbuoy}

The CMR SailBuoy is an unmanned surface ocean vessel capable of travelling the oceans for extended periods of time. It navigates the oceans autonomously - transmitting back data at regular intervals [16]. The SailBuoy can be used for a wide variety of ocean applications. From measuring ocean and atmospheric parameters to tracking oil spills or acting as a communication relay station for subsea instrumentation.

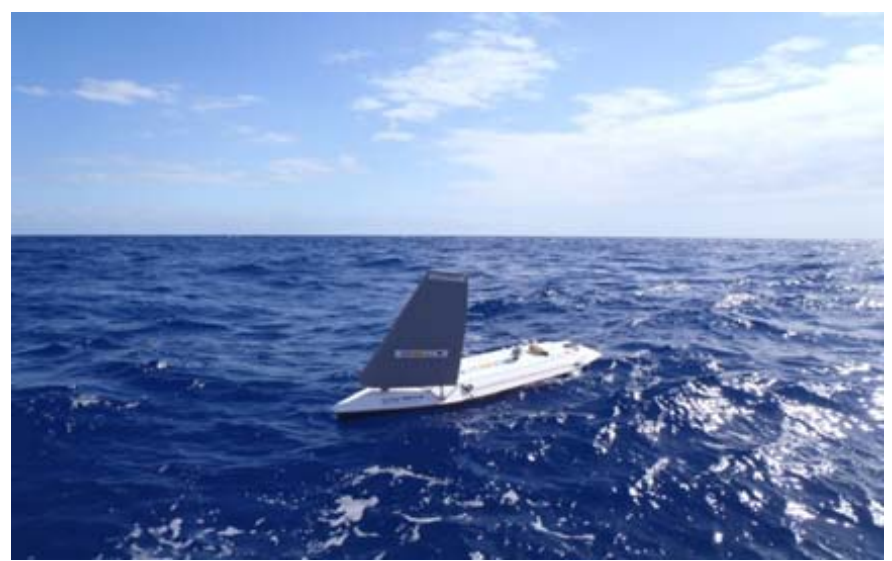

Fig. 7. Sailbuoy vehicle in operation across ocean waters.

\section{GLIDER MISSIONS}

During last three years, several missions for different purposes are underway in the Macaronesian area, promoted mainly by PLOCAN in cooperation with other local and external institutions/companies as a new way to monitor the surrounding waters of Canaries, Azores and Madeira. Some of the most representative examples of the performed and ongoing missions at regional, basin and global scale are listed as follow:

\section{A. Rapid Watch (2009-present)}

Through a cooperation agreement between NOCS (UK) and PLOCAN, since early 2010 is running an ongoing program of deployment and operation of a glider fleet from Gran Canaria within the operational program WATCH Rapid observation (monitoring of traffic South Atlantic ocean).

\section{B. INCOVBIO (2011)}

CNRS, CIMAAR Madeira and PLOCAN joined a mission in September 2011 with a main goal of study and characterize sub-mesoscale structures placed South Madeira Island, which play an important role in terms of productivity in the ocean.

\section{Challenger One (2011-present)}

The goal is to repeat the global scientific expedition by HMS Challenger between 1872 and 1876. Divided into different transects, the first one (currently operating) is between Iceland and Canary Islands. On June 23, 2011 staff by Teledyne Webb Research and PLOCAN deployed off Reykjavik coast a Slocum G2 glider named Silbo, recovered for refurbishment tasks in the Canary Islands in May 2012, having previously passed through the islands of Azores and Madeira. Piloted by scientists and technical staff of Rutgers University, ULPGC and PLOCAN, mission will provide information of high scientific value related to ocean circulation in the area. A second transect between the Canaries and the Caribbean region is on its way since July 2012, expecting to end in July 2013 at the Brazilian coast. 


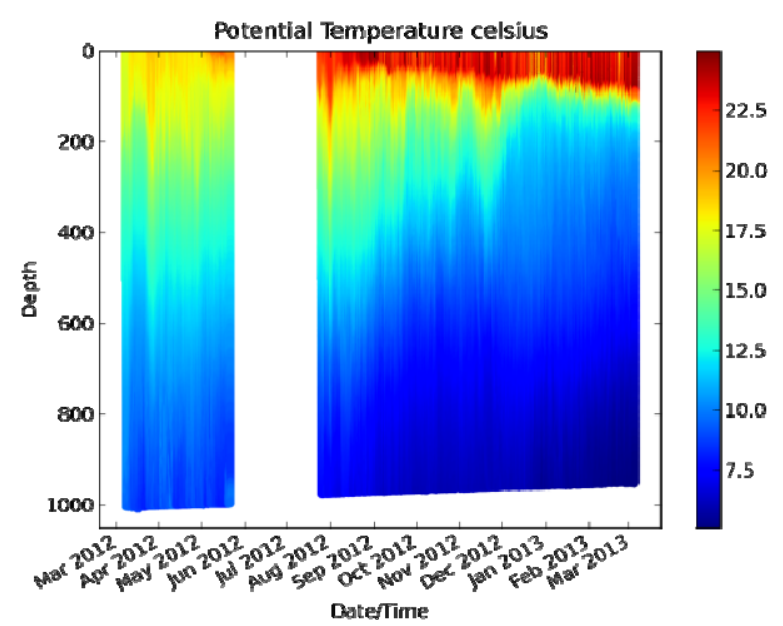

Fig. 8. Potential temperature derived form a section path between Açores and off-Cape Verde archipelago, gathered by Silbo Slocum glider under the framework of the Challenger One mission.

\section{VULCANO (2012)}

The VULCANO mission performed with the Hermes Waveglider in partnership with Liquid Robotics between $17^{\text {th }}$ May and $18^{\text {th }}$ Jun.2012 in El Hierro island, deployed/recovered from Gran Canaria. Payload configuration: SBE GP-CTD, Wetlabs Triplet Puck (Chl-A, Turbidity and Hydrocarbons), TRDI DVL and Airmar weather station.

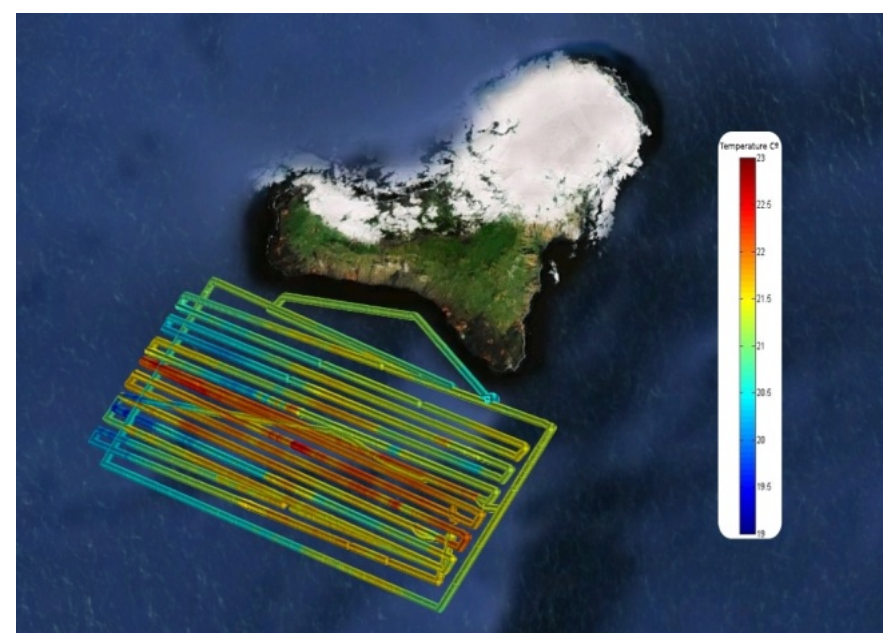

Fig. 9. Path described by Hermes Waveglider during the Vulcano mission in the surrounding waters of El Hierro Island. The plot shows the water temperature at seven meters depth.

\section{E. $S B-02$ (2012)}

The SB-002 was a partnership mission between PLOCAN and CMR (Norway) performed with a Sailbuoy unit from $13^{\text {th }}$ Nov. to $5^{\text {th }}$ Dec. 2012. The mission's goal focused on testing and evaluating technical aspects of the navigation and sampling site from the SailBuoy technology for a first time in subtropical areas as it is the Canary Islands archipelago, while to improve the ESTOC's monitoring program strategy. Payload sensor configuration was a NB-G-CTD and AADI Optode 4835. Sampling rate was $1 / 2$ hour for most of the time and increased to 0 hour during starting and ending mission periods.
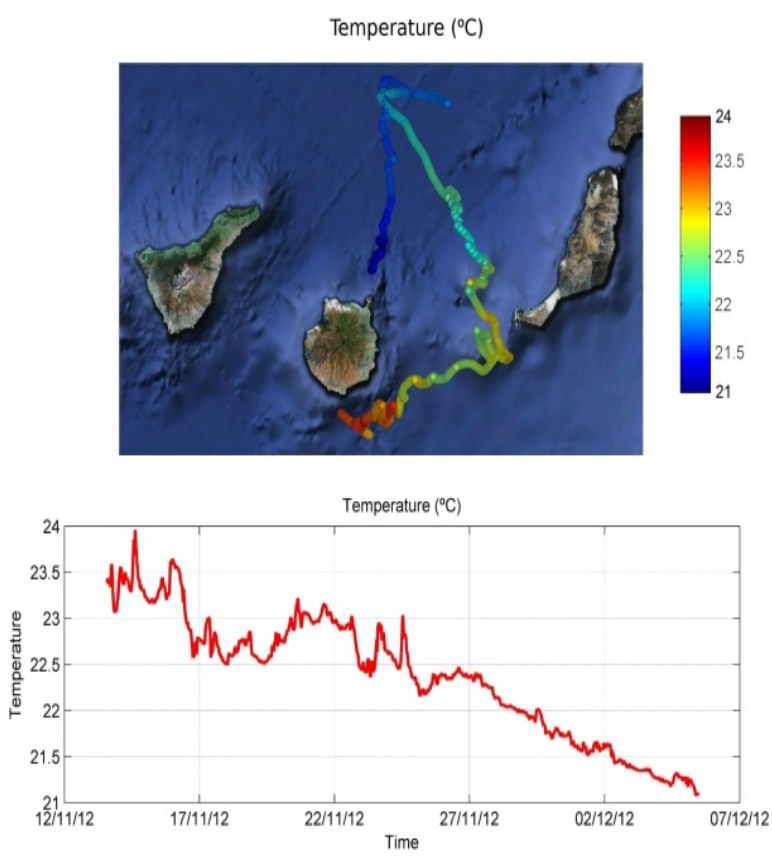

Fig. 10. Path described by SB02 Sailbuoy along track, overlapped with SST in Degrees Celsius.
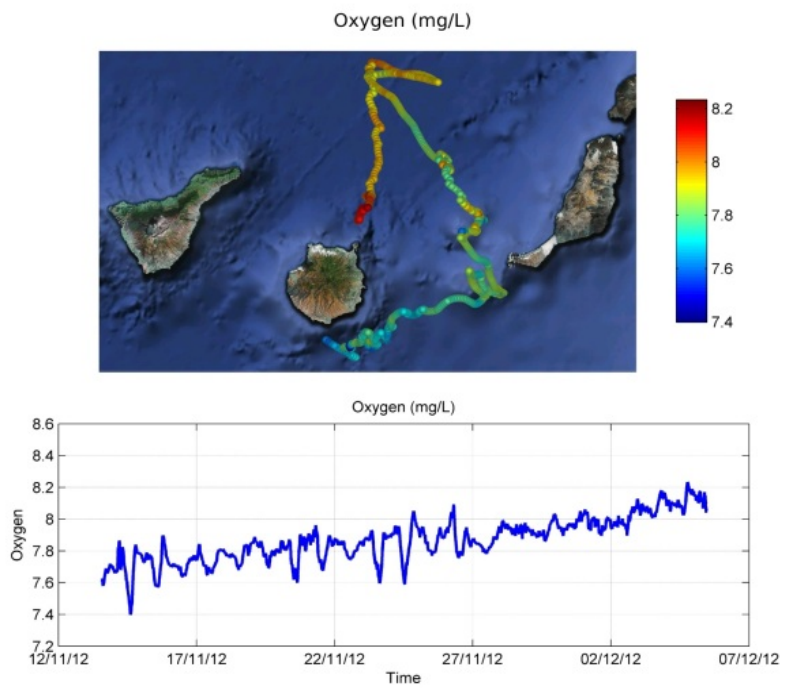

Fig. 11. Path described by SB02 Sailbuoy along track, overlapped with dissolved oxygen in $\mathrm{mg} / \mathrm{l}$.

\section{F. ESTOC (2011-present)}

The European Station for Time-Series in the Ocean ESTOC- is a site with a permanent multiplatform monitoring program since 1992, where gliders nowadays represent a keyone of the latest technologies able to provide data in NRT. After more than 15 years of active and in-situ operation by 
using a wide range of instruments and devices (oceanographic vessels, CTD / Rosette, XBT, moorings, synoptic, drifters,...) the ESTOC site has updated its permanent observational program with gliders as cutting-edge tools to maintain the sampling and continued occupation strategy, providing realtime data of great value to the scientific community and contribute with the standards from international programs where ESTOC (OceanSITES, EMSO, ICOS, among others) is included.

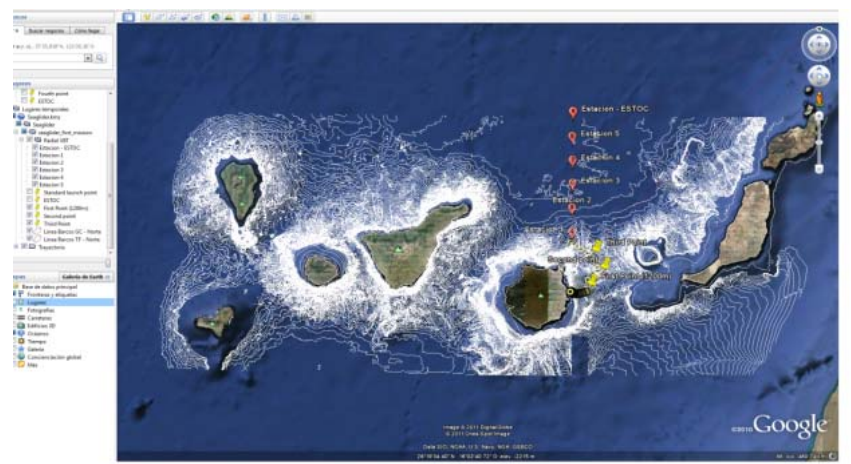

Fig. 12. The glider endurance line connecting the PLOCAN's observatory coastal node with the deep one (ESTOC) placed sixty nautical miles northwards Gran Canaria.

Different glider technologies (profilers and surface) are operated interchangeably to support a seasonal observations program. Primary sampled parameters are conductivity, temperature, dissolved oxygen, Chl-a, turbidity and CDOM. Gliders provide useful information for surface and intermediate water masses characterization (MMW, NASTMW, ENAW, MW, AAIW, etc.) in the area of interest.

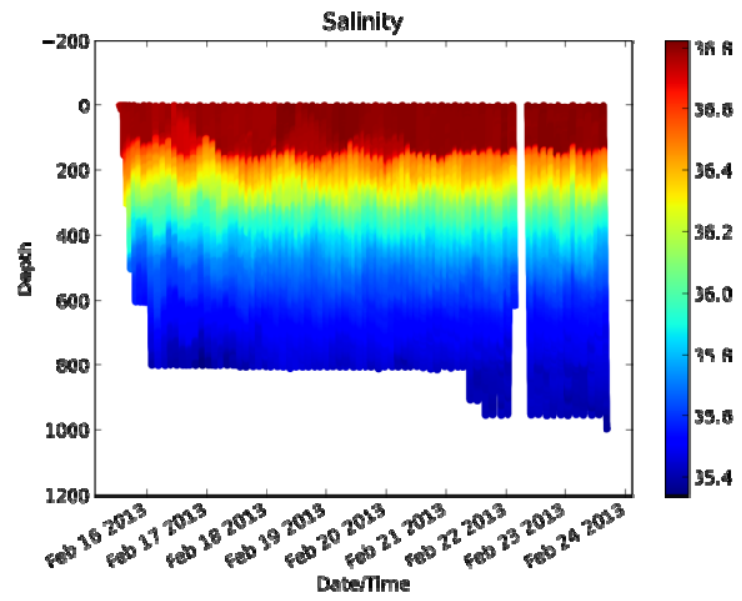

Fig. 13. Water column salinity data plot from performed transect across the ESTOC endurance line (PLOCAN's Extended Observatory as link between Ocean and Coastal Observatory nodes)

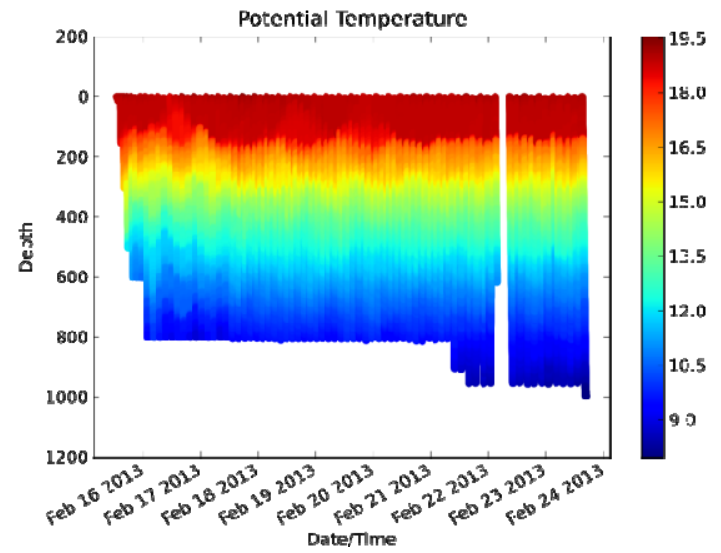

Fig. 14. Water column temperature data plot from performed transect across the ESTOC endurance line (PLOCAN's Extended Observatory as link between Ocean and Coastal Observatory nodes)

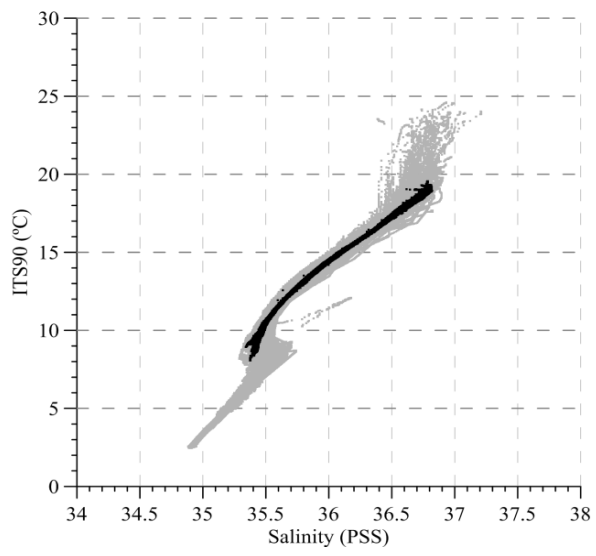

Fig. 15. TS plot displaying overlapped glider data and historical CTD gathered from research vessels since 1994.

\section{SG P301 ESTOC Mission}

$29^{\circ} \mathrm{N}$ Section

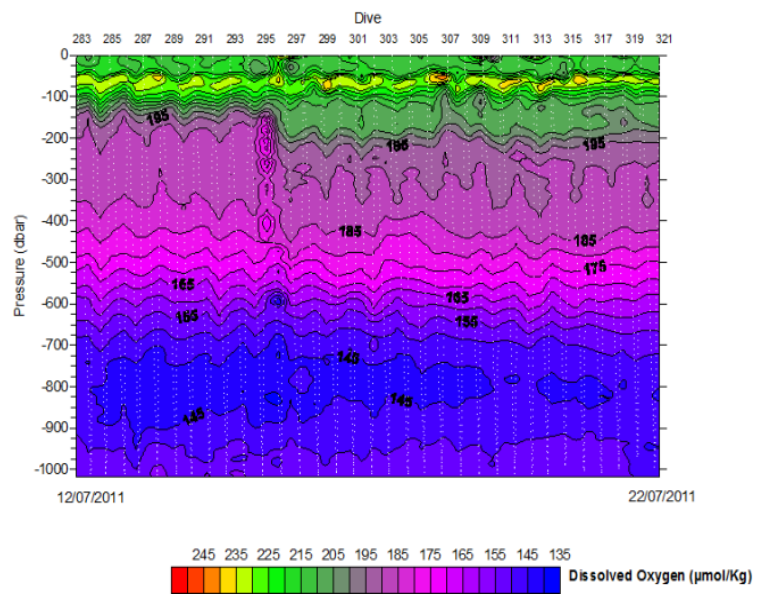

Fig. 16. Dissolved oxygen section across the $29^{\circ} \mathrm{N}$ gathered by the Seaglider unit SN. 525, within the framework of the endurance line at ESTOC Ocean Observatory site. 


\section{CONCLUSIONS}

A new ocean monitoring era is becoming a reality. Underwater and surface gliders, as new technological development, provide a valuable contribution to the sustained ocean observations in the coming decade, where the Macaronesian region through its R3M strategy isn't an exception. We are mainly limited by our imagination and available funding. Anticipated advances in biogeochemical sensors, payload capacity, battery duration, and ease-of-use will expand our ability to use gliders to monitor the physical and biogeochemical state of regional seas and boundary current systems (and marine protected areas, in particular), to understand responses and links to climate variability.

High-resolution physical and bio-geochemical data from gliders in these regions combined with the other components of the global observing system, will, without any doubt, allow us to fulfill far more objectives related to societal aspects (including marine security and "green" objectives) than is possible today. We anticipate that the glider component, which has relevance to process studies and monitoring, will be used actively, and in many places in the next decade will start to fill the gaps and to optimize the global network for the benefit for all observing and forecasting systems -global and regional/coastal ones- and all related applications.

Within this context, the Macaronesian region, with ESTOC/PLOCAN Ocean Observatory as reference site, is playing a relevant role as regional contribution to the main international initiatives in this context.

PLOCAN play an important role as dedicated facility infrastructure where new challenges from companies and institutions related to marine technology can reach in a costeffective and sustainable way the expected aims, and specifically engaged for such clever, helpful and fascinating ocean monitoring tools as surface and underwater gliders are.

\section{ACKNOWLEDGMENT (Heading 5)}

The authors truly acknowledge all institutions, companies and people involved in these challenging missions, with special mention to the EU-FP7 Program for funding the GROOM project within these sea operations have been partially carried out and supported. Special thank you addressed to Dr.Santana and Dr.Cianca for providing some key plots in this work. Also to thank all those technological partners like Teledyne Webb, Liquid Robotics, i-Robot and CMR companies for their support and collaboration. Finally, a special mention addressed to Las Palmas and Tenerife Harbourmaster authorizing the mission performance across to the described Macaronesian waters and the invaluable support from SAR crew members during some "unexpected" off-shore recoveries.

\section{REFERENCES}

[1] IOC - UNESCO, "An Implementation Strategy for the Coastal Module of the Global Ocean Observing System. GOOS Report, No 148, pp. 141, 2005.

[2] Llinás, O., M. J. Rueda, J.Pérez-Marrero, E.Pérez-Martell, R.Santana, M.G.Villagarcía, A.Cianca, J.Godoy and L.Maroto, "Variability of the
Antarctic Intermediate Waters in the Northern Canary Box", Deep Sea Research II,49(17), pp. 3441-3453, 2002.

[3] Cianca, A., J. M. Godoy, J. M. Martin, J. Pérez-Marrero, M. J. Rueda, O. Llinás, and S. Neuer, "Interannual variability of chlorophyll and the influence of low frequency climate modes in the North Atlantic subtropical gyre., Global Biogeochem. Cycles, doi:10.1029/2010GB004022, 2012 (in press).

[4] Stommel H., "The Slocum mission", Oceanography, 2 (1), pp. 22-25, 1989.

[5] Davis R., Eriksen C. and C. Jones, "Autonomous Buoyancy-driven underwater gliders", in The Technology and Applications of Autonomous Underwater Vehicles", G. Griffiths, ed., Taylor and Francis, London, 2002

[6] Claustre H., "Bio-Optical Profiling Floats as New Observational Tools for Biogeochemical and Ecosystem Studies: Potential Synergies with Ocean Color Remote Sensing." in these proceedings (Vol. 2), doi: 10.5270/ Ocean Obs09.cwp.17.

[7] Glenn S., Jones C., Twardowski, M., Bowers, L., Kerfoot J., Kohut J., Webb D. and O. Schofield, "Glider observations of sediment resuspension in a Middle Atlantic Bight fall transition storm", Limnol. Oceanogr., 53 (5, part 2), 2008, pp. 2180-2196

[8] Perry M.J., Sackman, B.S., Eriksen, C.C. \& C.M. Lee, "Seaglider observations of blooms and subsurface chlorophyll maxima off the Washington coast". Limnol. Oceanogr., 53(5, part 2), 2008, pp. 2169 2179

[9] Rudnick, D., Davis R., Eriksen C., Frantantoni D. \& M.-J. Perry, "Underwater Gliders for Ocean Research," Marine Technology Journal, vol. 38 , no. 1, Dec., 2004, pp. 48-59.

[10] Todd R. E., Rudnick D. L., R. E. Davis, and M. D. Ohman, "Underwater gliders reveal rapid arrival of El Niño effects off California's coast", Geophysical Research Letters, 38, doi:10.1029/2010GL046376, 2011.

[11] Send U., "OceanSITES. Proceedings of the "OceanObs'09: Sustained Ocean Observations and Information for Society". Conference (Vol. 2), Venice, Italy, 21-25 September, 2009, Hall. J. Harrison D.E. and Stammer, D., Eds., ESA Publication WPP-306, 2010.

[12] Simonetti P., "Slocum Glider: Design and 1991 Field Trials, Office of Naval Technology Contract N00014-90C-0098 Report, 1992.

[13] Jones C. "Slocum glider persistent oceanograpyh", IEEE Conference Publications, 2012

[14] Manley J. and Willcox S., "The wave glider: A persistent platform for ocean science", OCEANS'10-IEEE, Sydney, 2010.

[15] Osse T.J. and Eriksen C., "The Deepglider: A Full Ocean Depth Glider for Oceanographic Research. OCEANS'07 -IEEE, Vancouver, 2007.

[16] Fer, I., and D. Peddie, "Navigation performance of the SailBuoy", Bergen, Scotland mission, $12 \mathrm{pp}$, Christian Michelsen Research AS, Bergen, 2012. 